\title{
Fluoride Release and Its Enamel Uptake from Different Fluoride Releasing Products
}

\author{
Wahdan M. A. El-kwatehy ${ }^{1}$, Rabab I. Salama² \\ ${ }^{1}$ Department of Pediatric \& Dental Public Health and Preventive Dentistry, Faculty of Dentistry, \\ Mansoura University, Egypt and Faculty of Dentistry, Umm Al-Qura University, Saudi Arabia. \\ ${ }^{2}$ Department of Pediatric \& Dental Public Health and Preventive Dentistry, Faculty of Dentistry, \\ Mansoura University, Egypt.
}

Corresponding Author: Wahdan M. A. El-kwatehy

\begin{abstract}
Background: Professionally applied topical fluorides varnishes are used effectively to prevent dental caries.

Aim of the Work: The current study was designed to assess the rate of fluoride release from four fluoride products over 6 months' time period and determine the fluoride uptake by enamel.

Materials and Methods: An in vitro study was conducted on 60 extracted first premolars teeth classified randomly into four equal groups (15 teeth per group) according to the type of varnish used. The fluoride release was measured with Orion ${ }^{\mathrm{TM}}$ Fluoride Electrodes after one week, one month, three and six months and recorded as ppm. The fluoride uptake with enamel was evaluated under electron microscope after varnish application and 6 months later. Repeated ANOVA was used for comparison in each group for different time and one way ANOVA test for inter group comparison. Post hoc Tukey test and t test were used for paired group comparison.

Results: There were statistically significant differences regarding fluoride release among the four tested varnishes over the study follow up period (p less than 0.000 for all comparisons). The highest fluoride release occurs after application and gradually decreased with time. The total cumulative mean of fluoride released was higher among Enamel Seal and Varnish XT (51.85 and $51.57 \mathrm{ppm}$ ) followed by silver diamine fluoride $(49.46 \mathrm{ppm})$ and FluoroDip $(43.58 \mathrm{ppm})$. The enamel surfaces after varnishes application were smooth and nearly the same for the four applied varnishes but after 6 months all enamel surfaces appear porous with focal holes more observed in Enamel Seal and FluoroDip groups.

Conclusion: All tested fluoride varnish were releasing fluoride but each one has its own pattern. The sustainability of fluoride release from varnish XT and SDF was better than Enamel seal and FluoroDip varnishes.
\end{abstract}

Key words: Fluoride release, Enamel seal varnish, Varnish XT, Silver diamine fluoride, FluoroDip varnish, Scanning Electron Microscope.

\section{INTRODUCTION}

The dental caries initiated with the acids produced by cariogenic bacteria which attacking the inorganic components of tooth structure producing enamel demineralization. The dissociated inorganic minerals such as calcium and phosphorus will precipitate into tooth structure again when the surrounding oral environment changed toward alkaline $\mathrm{pH}$. The fluoride should be present at the right time with proper concentration in the oral cavity to increase the ability of tooth structure to uptake the mineral content through the process of remineralization [1].

Topical fluorides such as solutions, gels, foams and varnishes are professionally applied agents used effectively to prevent 
dental caries. The fluoride varnishes due to its ease of application have been used effectively for pre cooperative children, patients with exaggerated gag reflex, individuals at high caries risk needs special health care and those under radio therapy to head and neck tumors [2].

Delbem et al., studied the effect of fluoride varnish and silver diamine fluoride (SDF) on demineralization and they found that, fluoride containing varnish was reduced the depth of carious lesion and enamel surface demineralization more effective than SDF solution [3].

Fluoride varnishes can prevent dental caries in primary and permanent teeth of both children and adolescents and reduces the prevalence of caries in high-risk individuals [4,5], the application of fluoride varnishes twice/year is effective in the inhibition of caries progression [6-8].

Fluoride varnish application increases the fluoride in saliva but many factors such as the concentration of applied fluoride, delivery method, time since exposure, fluoride retention, and fluoride clearance from the oral cavity can influences the salivary concentration of fluoride [1]. Several studies indicated that, the greatest fluoride release take place at the first three weeks after application and gradually decreased with time [9-11].

Fluoride containing varnishes were created to extend the sustainability of fluoride and increase its uptake by the tooth structures. However, fluoride uptake might not be the principal mechanism of action of existing fluoride products, and the focus shifted to calcium fluoride-like compounds (CaF2) formation. The $\mathrm{CaF} 2$ crystals formed in the enamel and within plaque, will act as a reservoir releasing fluoride when the surrounding environment shifted toward acidic side and preventing demineralization and enhancing remineralization [12].

A lot of new topical fluoride products were introduced into the market such as Silver diamine fluoride (SDF), Clinpro ${ }^{\mathrm{TM}}$ XT Varnish, Titanium tetra fluoride and Tiefenfluorid and sodium fluoride fortified with bioactive glass. Many studies were carried out to assess the effectiveness of these agents on enamel and evaluate the longevity of its fluoride release in saliva and they concluded that, recent fluoride products released consistently and substantially more fluoride than conventional fluoride varnishes [13-16].

The clinician selects the fluoride releasing products based on extended time period of fluoride release, individual patient clinical presentation and provider preference. As a lot of previous in vitro studies were measured the amounts of fluoride released but not assess the fluoride uptake by enamel. The new topical fluoride products in the market are supposed to release fluoride slowly and for extended periods of time. The current study was designed to assess the rate of fluoride release from four fluoride products over 6 months follow up and determine the fluoride uptake by enamel.

\section{MATERIALS AND METHODS}

An in vitro study was performed to evaluate the surface changes and longevity release of fluoride from four different varnishes

\section{Sample size determination}

The required sample for this study was calculated using online calculator https://clincalc.com/stats/samplesize.aspx where the type I error was $5 \%$ and confidence level 95\%, with anticipated means concluded from previous studies [911] and the total minimal sample size calculated was 52 teeth.

\section{Sample selection}

Frist premolar teeth extracted due to orthodontic reason were collected and store in normal saline till starting the study. After teeth collections, it cleaned and dry then examined to exclude that with caries or cracked enamel. The final included number of teeth was 60 , all teeth surfaces were covered with nail varnish except a small 
area in the buccal surface with a size $3 \mathrm{~mm} x$ $3 \mathrm{~mm}$. the selected teeth were classified randomly into four equal groups each one contains 15 teeth according to the type of varnish used.

Group I: Enamel Seal Liquid (43.350 ppm F Tiefenfluorid, Humanchemie, Germany).

Enamel seal liquid is provided as two solutions. The first application solution contains Magnesium-hexafluorosilicate, copper-II-hexafluorosilicate, sodium fluoride (as stabilizer), distilled water. The second application solution contains Calciumhydroxide - highly dispersed, methylcellulose, distilled water.

Group II: Varnish XT $\left(3 \mathrm{M}^{\mathrm{TM}}\right.$ Clinpro $^{\mathrm{TM}}$ XT Varnish Durable Fluoride-Releasing Coating). Vanish XT varnish is a resin modified glass ionomer based on the patented methacrylate modified poly alkenoic acid. The liquid component consists primarily of poly alkenoic acid, HEMA (2-hydroxethylmethacrylate), water and initiators (including camphorquinone) plus calcium glycerophosphate. The paste is a combination of HEMA, BIS-GMA, water, initiators and fluoroaluminosilicate glass (FAS glass). According to the manufacture guide, the varnish is applied on clean surface by mixing it for $15 \mathrm{~min}$, apply thin coat, cure it for $20 \mathrm{~min}$ then wipe the coating with a moist cotton applicator.

Group III: Silver Diamine Fluoride (SDF) (Advantage Arrest Elevate Oral Care).

Unit dose ampules were used to ensure constant amount of varnish used. It contains 38\% Silver Diamine Fluoride, 25\% Silver, 5.5\% Fluoride and $8 \%$ Ammonia. The varnish applied to the dried tooth surface then the surface allowed to dry for 60 second.

Group IV: FluoroDip Bioactive (Prevest Denpro)

It is a sodium fluoride containing dental desensitizing varnish fortified with bio-glass for enhanced remineralization of enamel and dentine. FluoroDip Bioactive is an alcoholic suspension of sodium fluoride and bio-glass in natural shellac with artificial flavoring. $1 \mathrm{ml}$ of FluoroDip
Bioactive varnish contains $50 \mathrm{mg}$ of sodium fluoride equivalent to $22.6 \mathrm{mg}$ of fluoride.

\section{Sample storage}

The teeth were storage in plastic containers which were labelled with the group name and the date of storage, filled with $100 \mathrm{ml}$ of the artificial saliva with adjusted $\mathrm{pH}$ 7. After one week the sample were removed from the previous solutions and storage again in plastic containers contained fresh prepared artificial saliva, this process was repeated after one month, three months and six months. Old solutions were collected with their storage date the transfer for fluoride ions content analysis.

\section{Measurement of fluoride ions in the solutions:}

The storage solutions were collected with their storage date and a total ionic strength adjustment buffer (TISAB) III was used to adjust the $\mathrm{pH}$ of the solution to 5 5.5. The fluoride ions were measured with F-ISE (Model 9409; Orion, Thermo Scientific $^{\mathrm{TM}}$ Orion $^{\mathrm{TM}}$ Fluoride Electrodes) after one week, one month, three and six months and recorded as ppm.

\section{Scan Electron Microscope evaluation:}

A random sample of 5 teeth from each group were examined under electron microscope with magnification x 5000 after application of varnish specific for each group and again after 6 months at the end of the study.

\section{Validity of the data}

To ensure data validity, one of the examiners was responsible for the application procedures and the other one responsible for storage and fluoride analysis process.

\section{Statistical analysis}

The collected data was statistically analyzed using SPSS software version 23, repeated ANOVA was used for comparison in each group for different time evaluation and one way ANOVA test for inter group 

products.

comparison. Post hoc Tukey test and t test were used for paired group comparison, $p$ value less than 0.05 was considered statistically significant.

\section{RESULTS}

The findings of the current study indicated high releases of fluoride ions (24.72 ppm) after one week from varnishes applications among Enamel Seal group followed by Varnish XT and SDF groups, FluoroDip group showed the lowest mean value (19.46 ppm). Significant difference was found between the four groups ( $p$ < 0.000). After one month, Enamel Seal, Varnish XT and SDF groups showed nearly the same mean values of fluoride ions $(12.96, \quad 12.24$ and $12.57 \mathrm{ppm})$ while, FluoroDip group showed significant lower mean value of fluoride ions (11.32 ppm).
Varnish XT and SDF groups showed high mean values (11.85 and $11.54 \mathrm{ppm}$ ) of fluoride release after three months followed by Enamel Seal group (10.99 ppm) then FluoroDip group $(9.89 \mathrm{ppm})$. Significant difference was found between them ( $\mathrm{p}<$ 0.000). Similarly, after six months, Varnish $\mathrm{XT}$ and SDF groups still showed the highest mean values (4.95 and $4.06 \mathrm{ppm}$ ). Repeated ANOVA test showed significant differences for all varnishes groups regarding the time points of comparison $(p<0.000)$. the total cumulative mean of fluoride released was higher among Enamel Seal and Varnish XT groups (51.85 and $51.57 \mathrm{ppm})$, while FluoroDip group showed the lowest mean value $(43.58 \mathrm{ppm})$ with significant difference between the four varnishes groups $(\mathrm{p}<0.000)$. (Table 1, figure 1$)$

Table (1): The fluoride ions (ppm) released from different fluoride varnishes at four time points for measurements

\begin{tabular}{|c|c|c|c|c|c|c|}
\hline $\begin{array}{l}\text { Follow up } \\
\text { Varnish }\end{array}$ & $\begin{array}{l}\text { One week } \\
\text { Mean } \pm \text { SD }\end{array}$ & $\begin{array}{l}\text { One month } \\
\text { Mean } \pm \text { SD }\end{array}$ & $\begin{array}{l}\text { Three months } \\
\text { Mean } \pm \text { SD }\end{array}$ & $\begin{array}{l}\text { Six months } \\
\text { Mean } \pm \text { SD }\end{array}$ & $\begin{array}{l}\text { Total } \\
\text { Mean } \pm \text { SD }\end{array}$ & $\begin{array}{l}\mathbf{F}^{\#} \\
\text { (p value) }\end{array}$ \\
\hline Enamel Seal & $24.72 \pm 0.43$ & $12.96 \pm 0.25$ & $10.99 \pm 0.37$ & $3.18 \pm 0.14$ & $51.85 \pm 0.22$ & $\begin{array}{l}17.526 \\
(\mathrm{p}<0.000)^{*}\end{array}$ \\
\hline Varnish XT & $22.53 \pm 1.21$ & $12.24 \pm 0.34$ & $11.85 \pm 0.95$ & $4.95 \pm 0.95$ & $51.57 \pm 0.31$ & $\begin{array}{l}64.66 \\
(\mathrm{p}<0.000)^{*}\end{array}$ \\
\hline SDF & $21.29 \pm 1.45$ & $12.57 \pm 0.97$ & $11.54 \pm 1.08$ & $4.06 \pm 0.79$ & $49.46 \pm 0.48$ & $\begin{array}{l}35.91 \\
(\mathrm{p}<0.000)^{*}\end{array}$ \\
\hline FluoroDip & $19.46 \pm 0.54$ & $11.32 \pm 0.88$ & $9.89 \pm 1.01$ & $2.91 \pm 0.99$ & $43.58 \pm 0.62$ & $\begin{array}{l}31.77 \\
(\mathrm{p}<0.000)^{*}\end{array}$ \\
\hline $\begin{array}{l}\mathrm{F}^{\# \#} \\
\text { (p value) }\end{array}$ & $\begin{array}{l}67.49 \\
(p<0.000)^{*}\end{array}$ & $\begin{array}{l}73.53 \\
(p<0.000)^{*}\end{array}$ & $\begin{array}{l}16.89 \\
(\mathrm{p}<0.000)^{*}\end{array}$ & $\begin{array}{l}34.21 \\
(\mathrm{p}<0.000)^{*}\end{array}$ & $\begin{array}{l}27.46 \\
(\mathrm{p}<0.000)^{*}\end{array}$ & \\
\hline \multicolumn{7}{|c|}{$\begin{array}{l}\text { \# Repeated ANOVA test } F \text { value } \\
\text { \#\# One way ANOVA test } F \text { value } \\
\text { SD = standard deviation }\end{array}$} \\
\hline
\end{tabular}

Regarding the pairwise comparison between the varnish's groups, post hoc Tukey test was used for the comparison, after one week from the varnishes application there were significant difference between all groups. Non-significant differences were found between Enamel Seal group and both Varnish XT and SDF groups and between Varnish XT group and SDF group after one month from the application. On the other hand, significant differences were occurred between the other groups. After three months of applications SDF group showed non-significant difference with Enamel Seal group and Varnish XT group, on the other hand only the difference between Enamel Seal group and FluoroDip group was non-significant. Regarding the total cumulative fluoride released during the six months, the pair wise differences between the four groups were significant. (Table 2)

Regarding the Scanning Electron Microscope (SEM) images, after varnishes application the enamel surfaces for the four applied varnishes were smooth and nearly the same with some focal areas appear with Varnish XT and FluoroDip groups. After 6 months storage of the samples at $\mathrm{pH} 7$ all enamel surfaces appear porous with focal holes more observed in Enamel Seal and FluoroDip groups. (Figure 2) 
Wahdan M. A. El-kwatehy et.al. Fluoride release and its enamel uptake from different fluoride releasing products.

Table (2): The pairwise comparison between the different fluoride varnishes used regarding the fluoride released at the four time points of measurements

\begin{tabular}{|c|c|c|c|c|c|c|c|c|c|c|}
\hline & \multicolumn{2}{|c|}{ One week } & \multicolumn{2}{|c|}{ One month } & \multicolumn{2}{|c|}{ Three months } & \multicolumn{2}{|c|}{ Six months } & \multicolumn{2}{|l|}{ Total } \\
\hline & $\begin{array}{l}\text { Mean } \\
\text { diff }\end{array}$ & p value & $\begin{array}{l}\text { Mean } \\
\text { diff }\end{array}$ & p value & $\begin{array}{l}\text { Mean } \\
\text { diff }\end{array}$ & p value & $\begin{array}{l}\text { Mean } \\
\text { diff }\end{array}$ & p value & $\begin{array}{l}\text { Mean } \\
\text { diff }\end{array}$ & p value \\
\hline $\begin{array}{lll}\text { Enamel Seal } & \text { Vs } \\
\text { Varnish XT } & \end{array}$ & 2.19 & $<0.000^{*}$ & 0.72 & 0.060 & -0.86 & $0.020^{*}$ & -1.77 & $<0.000^{*}$ & 0.28 & $0.010^{*}$ \\
\hline Enamel Seal Vs SDF & 3.34 & $<0.000^{*}$ & 0.39 & 0.287 & -0.55 & 0.137 & -0.88 & $0.020^{*}$ & 2.39 & $<0.000^{*}$ \\
\hline $\begin{array}{lll}\text { Enamel } & \text { Seal } & \text { Vs } \\
\text { FluoroDip } & & \\
\end{array}$ & 5.26 & $<0.000^{*}$ & 1.64 & $<0.000^{*}$ & 1.10 & $0.004^{*}$ & 0.27 & 0.441 & 8.27 & $<0.000^{*}$ \\
\hline Varnish XT Vs SDF & 1.24 & $0.010^{*}$ & -0.33 & 0.366 & 0.31 & 0.241 & 0.89 & $0.020^{*}$ & 2.11 & $<0.000^{*}$ \\
\hline $\begin{array}{l}\text { Varnish XT Vs } \\
\text { FluoroDip }\end{array}$ & 3.07 & $<0.000^{*}$ & 0.92 & $0.020^{*}$ & 1.96 & $<0.000^{*}$ & 2.04 & $<0.000^{*}$ & 7.99 & $<0.000^{*}$ \\
\hline SDF Vs FluoroDip & 1.83 & $<0.000^{*}$ & 1.25 & $0.001^{*}$ & 1.65 & $<0.000^{*}$ & 1.15 & $0.003^{*}$ & 5.88 & $<0.000^{*}$ \\
\hline
\end{tabular}

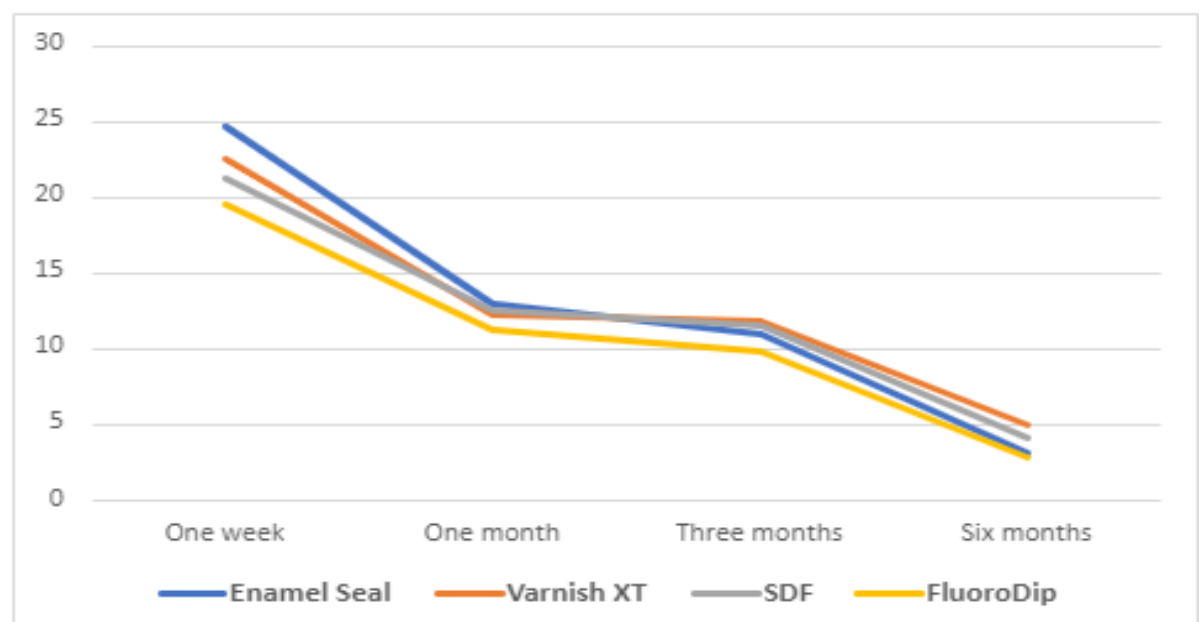

Figure (1): Comparison between the fluoride released from different fluoride varnishes at the four time points of measurements

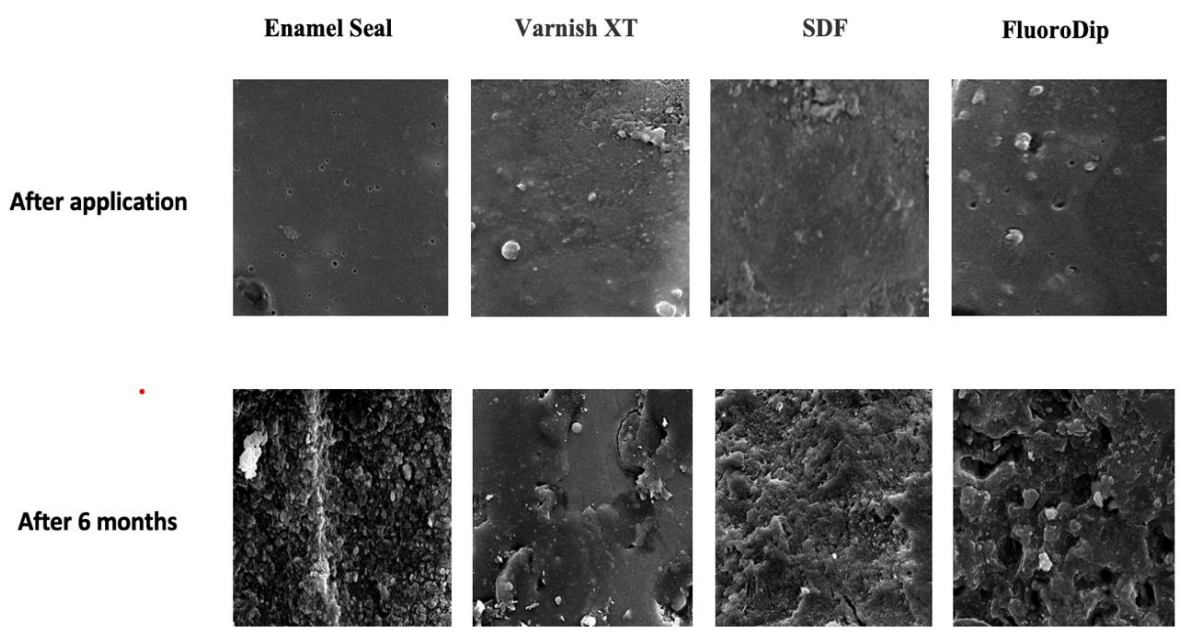

Figure (2): Enamel surface image by SEM (X5000) after the different varnishes' application and after 6 months storage in artificial saliva at pH 7.

\section{DISCUSSION}

Dental public healthcare workers know that; until now there is no restorative materials equal in its chemical and physical properties to normal tooth structures. So, the main aim of modern preventive dentistry is to preserve and maintain the natural tooth structure at healthy condition.

Fluoride was very effective in caries prevention because inhibiting remineralization and increasing remineralization. Fluoride varnishes were 
used to increase the contact between fluoride and enamel as it covers the teeth as an adherent film for at least 24 hours. Fluoride varnishes were used as standard practice for the professionally applied preventive measures for dental caries [1720].

There are a lot of fluoride varnishes at the market and a lot of them release fluoride but the rate did not the same among them, the variation in the fluoride release and its longevity have been reported in previous studies $[11,21]$ but there were no studies determine fluoride uptake by the enamel. So, the current study was designed to compare fluoride release from commercially available fluoride varnishes and determine the fluoride uptake by enamel and guiding the health care workers and clinician for proper selection of fluoride varnish for prevention of dental diseases.

The results of the current study indicated that; there were significant differences among the different studied varnishes for releasing fluoride, also, there were significant differences among different follow up intervals indicating differences in longevity of fluoride release from these varnishes (Table 1 and Fig.1). Although Enamel Seal and varnish XT have the highest fluoride release, the differences between them were significant at all follow up except at the 1 month. The high fluoride release from enamel seal at one weak may be due to its formulation and application, the first application solution activated the enamel and allowed the complex fluor- and copper-ions enter deep into the enamel and the second application solution enters deep and causes immediate reaction in the depth of the enamel releasing fluoride.

Both varnish XT and SDF have fluoride releasing rates significantly higher than FluoroDip at all follow up intervals. The differences between varnish XT and SDF were significant at 1 week and 6 months but not significant at 1 and 3 months follow up (table 2). These variations may be due to the different properties of carriers for fluoride in the available fluoride varnishes.
Regarding longevity of fluoride release in the present study; the varnish XT and SDF were released fluoride more than Enamel seal and FluoroDip varnishes for 6 months period. The varnish XT was released $22.53 \pm 1.21 \mathrm{ppm}$ after one week of its application and gradually decreased to $4.95 \pm 0.95$ after 6 months (Table 1 and fig. $1)$, these results were agreed with the previous study which reported that varnish XT was gradually decreased from $18.78 \pm$ $7.35 \mathrm{ppm}$ of fluoride to $9.78 \pm 4.11 \mathrm{ppm}$ after 6 months. The sustained fluoride release from varnish XT may be due to the chemical bond between glass ionomer and tooth structure $[22,23]$. The substantially released fluoride from varnish XT and SDF support the results obtained by Delbem et al and Virupaxi et al [3,24].

In the present study, all of tested varnishes released fluoride from the start to the end of the study with the highest release occurred at the first week. At first week and first month, Enamel seal had the highest fluoride releasing level followed by varnish $\mathrm{XT}$ and SDF and the least one was FluoroDip. At the third and sixth months follow up, varnish XT and SDF have the highest releasing level followed by Enamel seal and FluoroDip (Table 1 and Figure 1), these findings were agreed with the previous studies which concluded the same results $[9,10,21]$.

Scanning Electron Microscope (SEM) images revealed some focal areas appear with Varnish XT and FluoroDip groups immediately after application, this may be due to higher viscosity of those varnishes than Enamel seal liquid and SDF. After 6 months all enamel surfaces appear porous with focal holes more observed in Enamel Seal and FluoroDip groups (Figure 2 ), the roughness of the enamel surface may be due to decreased fluoride release which lead to reduction in calcium fluoride deposition on enamel surface.

The focal holes were less in varnish XT because it is a light cured resin modified glass ionomer that releases calcium, fluoride and phosphorus which may improve mineral 
uptake by enamel. Also, porous surface of enamel after SDF may be due to thin thickness of enamel as previous study indicated that, the reactivity of silver diamine fluoride was higher on dentin than on enamel and recommended to increase the frequency of its application for enamel caries prevention [24].

\section{CONCLUSIONS}

According the present results, it could conclude that:

1. All tested fluoride varnish were releasing fluoride but each one has its own pattern.

2. The sustainability of fluoride release from recent varnishes (varnish XT and SDF) was better than conventional varnishes (Enamel seal liquid and FluoroDip varnish).

\section{Limitations of the Study}

1. The present in vitro study cannot evaluate the effect of dynamic changes of salivary $\mathrm{pH}$ inside oral cavity on fluoride release from the varnishes successfully.

2. The qualitative evaluation of mineral uptake using SEM not indicating the actual amount of mineral gained by enamel from varnish application.

\section{Recommendations}

1. The dental public health care workers should be encouraged to use fluoride varnish XT and SDF for caries prevention, as they provided high fluoride levels encourage the remineralization process.

2. The fluoride uptake by enamel needs further investigation using quantitative methods rather than qualitative one.

Acknowledgement: None

Conflict of Interest: None

Source of Funding: None

Ethical Approval: Approved

\section{REFERENCES}

1. Jablonowski BL, Bartoloni JA, Hensley DM, Vandewalle KS. Fluoride release from newly marketed fluoride varnishes. Quintessence Int 2012; 43(3):221-228.

2. Ritwik P, Aubel JD, Xu X, Fan Y, Hagan J. Evaluation of short-term fluoride release from fluoride varnishes. J Clin Pediatr Dent 2012; 36(3):2758.

3. Delbem ACB, Bergamaschi M, Sassaki kt., Cunha RF. Effect of fluoridated varnish and silver diamine fluoride solution on enamel demineralization: $\mathrm{pH}$-cycling study. J Appl Oral Sci 2006; 14(2):88-92.

4. Weintraub JA, Ramos-Gomez F, Jue B, Shain S, Hoover CI, Featherstone JD, et al. Fluoride varnish efficacy in preventing early childhood caries. J Dent Res 2006; 85(2):172-176.

5. American Dental Association Council on Scientific Affairs. Professionally applied topical fluoride: Evidence-based clinical recommendations. J Am Dent Assoc 2006; 137(8):1151-1195.

6. Marinho VC, Higgins JP, Logan S, Sheiham A. Fluoride varnishes for preventing dental caries in children and adolescents. Cochrane Database Syst Rev 2002;3:CD002279.

7. Petersson LG, Twetman S, Dahlgren H, Norlund A, Holm AK et al. Professional fluoride treatment for caries control: a systematic review of clinical trials. Acta Odontol Scand 2004;62(3):170-176.

8. Carvalho DM, Salazar M, Oliveira BH, Coutinho ES. Fluoride varnishes and decrease in caries incidence in preschool children: a systematic review. Rev Bras Epidemiol 2010;13(1):139-149.

9. Castillo JL, Milgrom P. Fluoride release from varnishes in two in vitro protocols. $\mathrm{J}$ Am Dent Assoc 2004; 135(12):1696-1699.

10. Eakle WS, Featherstone JD, Weintraub JA, Shain SG, Gansky SA. Salivary fluoride levels following application of fluoride varnish or fluoride rinse. Community Dent Oral Epidemiol 2004; 32(6):462-469.

11. Shen C, Autio-Gold J. Assessing fluoride concentration uniformity and fluoride release from three varnishes. J Am Dent Assoc 2002; 133(2):176-182.

12. Vogel Gl. Oral fluoride reservoirs and the prevention of dental caries. Monogor Oral Sci 2011; 22: 146-157.

13. Meto A, Meto Ag, Tragaj E, Lipo M, Bauermann C. The use of Tiefenfluorid for 
Wahdan M. A. El-kwatehy et.al. Fluoride release and its enamel uptake from different fluoride releasing products.

desensitization of dentinal hyperesthesia. Balk J Dent Med 2014; 18:85-88

14. Comar LP, de Souza BM, Grizzo LT, Buzalaf MAR, Magalhaes AC. Evaluation of fluoride release from experimental $\mathrm{TiF}$ and $\mathrm{NaF}$ varnishes in vitro. $\mathbf{J}$ Appl Oral Sci 2014; 22(2): 138-143.

15. Virupaxi SG, Roshan NM, Poornima P, Nagaveni NP, Neena IE, Bharath KP. Comparative Evaluation of Longevity of Fluoride Release From Three Different Fluoride Varnishes - An Invitro Study. J Clin Diag Res 2016;10(8): ZC33-ZC36

16. ADA Professional Product Review; Fluoride Varnish and Silver Diamine Fluoride: Fluoride Release Analysis and Clinical Guidance. 2017; 12(2).

17. Seppa L, Leppanen T, Hausen H. Fluoride varnish versus acidulated phosphate fluoride gel: a 3-year clinical trial. Caries Res 1995; 29(5):327-330.

18. Munshi AK, Reddy NN, Shetty V. Comparative evaluation of three fluoride varnishes: an in-vitro study. J Indian Soc Pedod Prev Dent 2001; 19(3):92-102.

19. Zimmer S, Robke FJ, Roulet JF. Caries prevention with fluoride varnish in a socially deprived community. Community Dent Oral Epidemiol 1999; 27(2):103- 108.

20. Autio-Gold JT, Courts F. Assessing the effect of fluoride varnish on early enamel carious lesions in the primary dentition. $\mathbf{J}$ Am Dent Assoc 2001; 132(9):1247- 1253.

21. Virupaxi S, Roshan N, Poornima P, Nagaveni N, Neena I, Bharath K. Comparative Evaluation of Longevity of Fluoride Release from Three Different Fluoride Varnishes - An Invitro Study. J Clin Diag Res 2016; 10(8): 33-36.

22. 3M ESPE. Vanish XT extended contact varnish. Available at: solutions. $3 \mathrm{~m}$. com.au/wps/portal/3M/en_AU/3M-ESPE-

APAC/dental-professionals/products/ category/preventive/vanish-xt

23. Powers JM, Sakaguchi RL. Preventive materials. Craigs restorative dental materials. St. Louis: Mosby/Elsevier, 2006, p 161.

24. Twetman S, Skold-Larsson K. Fluoride concentration in whole saliva and separate gland secretions after topical treatment with three different fluoride varnishes. Acta Odontol Scand 1999; 57(5):263-266.

How to cite this article: Wahdan M. A. Elkwatehy, Salama RI. Fluoride release and its enamel uptake from different fluoride releasing products. Int J Health Sci Res. 2021; 11(10): 272-279. DOI: https://doi.org/10.52403/ijhsr. 20211036 